\title{
Assessment of Pollen Viability, Germination, and Tube Growth in Eight Tunisian Caprifig (Ficus carica L.) Cultivars
}

\author{
Badii Gaaliche, ${ }^{1}$ Afifa Majdoub, ${ }^{2}$ Mehdi Trad, ${ }^{1}$ and Messaoud Mars ${ }^{1}$ \\ ${ }^{1}$ Research Unit on Agrobiodiversity, Department of Horticultural Sciences, Higher Institute of Agricultural Sciences, \\ University of Sousse, 4042 Chott Mariem, Tunisia \\ ${ }^{2}$ Centre Régional des Recherches en Horticulture et Agriculture Biologique de Chott-Mariem, BP 57, 4042 Chott Mariem, Tunisia
}

Correspondence should be addressed to Badii Gaaliche; badiigaaliche@yahoo.fr

Received 15 May 2013; Accepted 18 June 2013

Academic Editors: O. Ferrarese-Filho and J. Hatfield

Copyright (C) 2013 Badii Gaaliche et al. This is an open access article distributed under the Creative Commons Attribution License, which permits unrestricted use, distribution, and reproduction in any medium, provided the original work is properly cited.

\begin{abstract}
The evaluation of pollen viability and its germination capacity are two essential criteria for pollinator's characterization. This study was carried out to evaluate pollen quality of eight caprifigs grown in the center-east and north-west of Tunisia. Two colorimetric tests 2,3,5-triphenyl tetrazolium chloride (TTC) and acetocarmine were used to estimate pollen viability. Germination rate and pollen tube growth in a culture medium containing 5\% sucrose, $5 \mathrm{ppm}$ boric acid $\left(\mathrm{H}_{3} \mathrm{BO}_{3}\right)$ and $1 \%$ agar were registered after 24, 48, and 72 hours $(\mathrm{H})$ of incubation. Results showed that the highest pollen viability rate (84\%) was obtained by TTC test in caprifig Assafri, followed by Jrani (80.2\%), Djebba 2 (77.8\%), and Djebba 1 (73.6\%). That of other caprifigs did not exceed $50 \%$ for the two tests. In all caprifig types, germination rate and pollen tube growth varied according to the incubation period. The highest percentage of germination $(72 \%)$ and maximum pollen tube length $(960 \mu \mathrm{m})$ were recorded after $72 \mathrm{H}$ of incubation in caprifigs Assafri and Jrani, respectively. Among the caprifigs studied, four types (Assafri, Jrani, Djebba 1, and Djebba 2) appeared to be suitable pollinators with respect to the criteria investigated.
\end{abstract}

\section{Introduction}

Fig tree (Ficus carica L.) is a typical species of Mediterranean countries. It has been cultivated since ancient times and is mentioned in the holy Quran, Christian bibles, and the Hebrew [1]. The fig is an important fruit worldwide for dry and fresh consumption, and recently their nutritive and pharmacological values have been investigated [2-4]. In nature, this tree is present in two sexual forms, the domesticated fig (female tree and producer of the edible fruit) and the caprifig (male tree) which provides the source of pollen for commercial fig plantings [5]. Fig pollen is carried by a unique wasp (Blastophaga psenes L.), that has coevolved with the fig tree [6].

In Tunisia, fig is one of the fruit crop species better adapted to different environmental areas and soils. Fig plantations are widespread over the country, and traditional methods of cultivation are still used [7]. The caprification (pollination) is quite a common practice in all regions and was cited as an important factor affecting the yield and quality of fig fruits $[4,8]$. Prospection made in different regions permitted the identification of many male fig ecotypes. Several are cultivated and received names [9]. Many others are unnamed but regularly used by farmers. Differences were noted for fruit characteristics and date of pollen maturity $[7,10]$. Fig pollinator, because of ecological conditions, might be scarce. In some continental areas, caprifigs are rare and low winter temperatures impede the fig wasp to fulfil its life cycle. As well as the nonsynchronicity of the ripening of caprifigs and receptivity of the female edible figs, the lack of selected pollinators according to the requests of female cultivars and cultivation areas is a major constraint $[11,12]$. Caprifig trees with good quality and quantity of pollen viable are essential for a good caprification [13]. In general, there is a linear relation between pollen viability and germination capability in many fruit species [14]. Germination capability of pollen depends on various factors, namely, nutrition conditions of species, varieties used, and environmental factors [15]. To investigate pollination potential, estimates should be made of 
TABLE 1: Studied caprifig cultivars.

\begin{tabular}{lcc}
\hline Number & Caprifigs & Geographical origin \\
\hline 1 & Assafri & Center-east (Bekalta) \\
2 & Jrani & Center-east (Bekalta) \\
3 & Bithri & Center-east (Mahdia) \\
4 & Hemri & Center-east (Mahdia) \\
5 & Djebba 1 & North-west (Djebba) \\
6 & Djebba 2 & North-west (Djebba) \\
7 & Djebba 3 & North-west (Djebba) \\
8 & Djebba 4 & North-west (Djebba) \\
\hline
\end{tabular}

pollen quantity and viability, as well as of pollen germination capability.

In this study, we examined pollen grains for viability, germinability, and rate of pollen tube growth in eight Tunisian caprifig cultivars with the aim of identifying the most suitable pollinators for fig female orchard establishment. This information is expected to be useful to plant breeders, geneticers, or genebank curators who need pollen viability tests.

\section{Materials and Methods}

The present study was carried out to evaluate the pollen quality of eight caprifig cultivars cultivated in the two center-east regions of Tunisia (Bekalta and Mahdia) and the north-west region (Djebba) (Table 1). Pollen collection was done according to the technique adopted by Storey [16]. Twenty profichis (caprifigs) per cultivar were harvested in full maturity period (June-July) and transferred to the laboratory. Ripe caprifigs were taken to a warm, dry place, split open longitudinally, and spread out to dry on similar paper on laboratory bench. After 2-3 days, fruits were dried and all of anthers have dehisced. The pollen was released on paper and placed in Petri dishes. It was stored at $4^{\circ} \mathrm{C}$ in a refrigerator until use.

Pollen viability was estimated using two colorimetric tests, that is, 2,3,5 triphenyl tetrazolium chloride (TTC) [17] and acetocarmine [14]. Both methods consist to the addition of colorant on pollen and observation under photonic microscope (Leica DM LB). The pollen viability was scored according to staining level (pollen with bold red colour as viable and colourless as nonviable). The percentage of pollen viability was determined as the ratio of the number of viable grains to the total grains number.

In vitro germination was assessed with the hanging drop method [14]. Pollen germination and pollen tube growth were determined by placing a small drop of germinating media on a cover glass; pollen grains were sown on the drops with a clean brush, and the cover glass was then inverted and rested on the cavity slide. Pollen was incubated under dark conditions at $25^{\circ} \mathrm{C}$ in a culture medium containing 5\% sucrose, 5 ppm boric acid $\left(\mathrm{H}_{3} \mathrm{BO}_{3}\right)$, and $1 \%$ agar $[18,19]$ for 24,48 , and 72 hours of time. For each incubation period, germination was recorded in three drops by counting three fields. A pollen grain was considered germinated when pollen tube length was at least equal to or greater than the grain
TABLE 2: Pollen viability rates for caprifig cultivars.

\begin{tabular}{lcc}
\hline Cultivars & \multicolumn{2}{c}{ Pollen viability (\%) determined by } \\
Acetocarmine & TTC \\
\hline Assafri & $80.0^{\mathrm{a}}$ & $84.0^{\mathrm{a}}$ \\
Jrani & $76.4^{\mathrm{a}}$ & $80.2^{\mathrm{a}}$ \\
Bithri & $52.8^{\mathrm{b}}$ & $55.3^{\mathrm{b}}$ \\
Hemri & $54.2^{\mathrm{b}}$ & $50.9^{\mathrm{b}}$ \\
Djebba 1 & $71.0^{\mathrm{a}}$ & $73.6^{\mathrm{a}}$ \\
Djebba 2 & $75.2^{\mathrm{a}}$ & $77.8^{\mathrm{a}}$ \\
Djebba 3 & $49.2^{\mathrm{b}}$ & $45.7^{\mathrm{b}}$ \\
Djebba 4 & $47.1^{\mathrm{b}}$ & $50.0^{\mathrm{b}}$ \\
\hline F-value & $16.29^{* *}$ & $19.46^{* *}$ \\
\hline
\end{tabular}

Mean in each column followed by the same letters are not significantly different at $P<0.05$ according to Duncan's multiple range test. ${ }^{* *}$ Significant at $P<0.01$.

diameter [15]. Germination percentage (\%) was determined by dividing the number of germinated pollen grains per field of view by the total number of pollen per field of view. Measurements of pollen tube length $(\mu \mathrm{m})$ were recorded directly by an ocular micrometer fitted to the eyepiece of the microscope. Mean pollen tube length was calculated as the average length of 20 pollen tubes measured from each drop.

For each measured variable, data were analyzed statistically by running ANOVA of Statistical Package for the Social Sciences (SPSS) version 13.0. The mean values were compared using Duncan's multiple range test $(P<0.05)$.

\section{Results and Discussion}

3.1. Pollen Viability. Significant differences $(P<0.01)$ among caprifig cultivars were found in pollen viability for the two tests carried out. The percentage of pollen viability varied from 47.1 to $80 \%$ by acetocarmine test and from 45.7 to $84 \%$ by TTC test. In general, acetocarmine and TTC tests did not differ much in determining the viability of pollen (Table 2 ). The highest percentage of viable pollen (84\%) was recorded with TTC in caprifig Assafri, followed by Jrani (80.2\%), Djebba 2 (77.8\%), and Djebba 1 (73.6\%). The rates of pollen viability for the other caprifigs did not exceed $55 \%$ for the two tests (Table 2). These results corroborate those of Ilgin et al. [17] who reported that percentage of viable pollen in Turkish caprifigs ranged from 76.04 to $83.34 \%$ by TTC test and from 75.60 to $86.73 \%$ by fluorescein diacetate (FDA) test. The caprifigs (Assafri and Jrani) from the center-east and those (Djebba 1 and Djebba 2) from the north-west showed high amounts of viable pollen with the two dyes. Thus, TTC or acetocarmine can be recommended for testing pollen viability of caprifigs. Results were also in agreement with other studies indicating that the use of different colorants to test pollen viability may give comparable results $[17,20,21]$.

3.2. Pollen Germination and Pollen Tube Growth. Based on the observations made under photonic microscope, it was noted that pollen germination rates and pollen tube growth 
TABLE 3: Average values of germination rates and pollen tube lengths after 24,48 , and 72 hours $(\mathrm{H})$ of incubation for caprifig cultivars.

\begin{tabular}{|c|c|c|c|c|c|c|}
\hline \multirow{2}{*}{ Cultivars } & \multicolumn{3}{|c|}{ Germinations rates (\%) after } & \multicolumn{3}{|c|}{ Pollen tube length $(\mu \mathrm{m})$ after } \\
\hline & $24 \mathrm{H}$ & $48 \mathrm{H}$ & $72 \mathrm{H}$ & $24 \mathrm{H}$ & $48 \mathrm{H}$ & $72 \mathrm{H}$ \\
\hline Assafri & $30.4^{\mathrm{bc}}$ & $65.7^{\mathrm{a}}$ & $72^{\mathrm{a}}$ & $518.8^{\mathrm{a}}$ & $700.0^{c}$ & $715.0^{\mathrm{bc}}$ \\
\hline Jrani & $38.6^{\mathrm{a}}$ & $60.0^{\mathrm{b}}$ & $66^{\mathrm{ab}}$ & $454.2^{\mathrm{b}}$ & $871.5^{\mathrm{a}}$ & $960.0^{\mathrm{a}}$ \\
\hline Bithri & $15.0^{\mathrm{d}}$ & $18.3^{\mathrm{e}}$ & $33^{\mathrm{c}}$ & $182.3^{\mathrm{c}}$ & $354.1^{\text {de }}$ & $390.7^{\mathrm{d}}$ \\
\hline Hemri & $12.2^{\mathrm{de}}$ & $25.1^{\mathrm{d}}$ & $30^{\mathrm{cd}}$ & $221.0^{c}$ & $370.0^{\mathrm{d}}$ & $375.0^{\mathrm{d}}$ \\
\hline Djebba 1 & $27.1^{\mathrm{c}}$ & $68.5^{\mathrm{a}}$ & $64^{\mathrm{b}}$ & $414.6^{\mathrm{b}}$ & $779.8^{\mathrm{b}}$ & $786.4^{\mathrm{b}}$ \\
\hline Djebba 2 & $35.3^{\mathrm{ab}}$ & $70.9^{\mathrm{a}}$ & $71.5^{\mathrm{a}}$ & $510.0^{\mathrm{a}}$ & $663.2^{c}$ & $697.1^{c}$ \\
\hline Djebba 3 & $7.5^{\mathrm{ef}}$ & $40.2^{\mathrm{c}}$ & $36^{\mathrm{c}}$ & $189.2^{\mathrm{C}}$ & $229.0^{f}$ & $416.2^{\mathrm{d}}$ \\
\hline Djebba 4 & $2.5^{\mathrm{f}}$ & $10.7^{\mathrm{f}}$ & $25^{\mathrm{d}}$ & $176.9^{c}$ & $300.0^{\mathrm{e}}$ & $366.0^{\mathrm{d}}$ \\
\hline$F$-value & $48.35^{* *}$ & $152.6^{* *}$ & $79.34^{* *}$ & $67.58^{* *}$ & $124.78^{* *}$ & $68.44^{* *}$ \\
\hline
\end{tabular}

Mean in each column followed by the same letters is not significantly different at $P<0.05$ according to Duncan's multiple range test. ${ }^{* *}$ Significant at $P<0.01$.

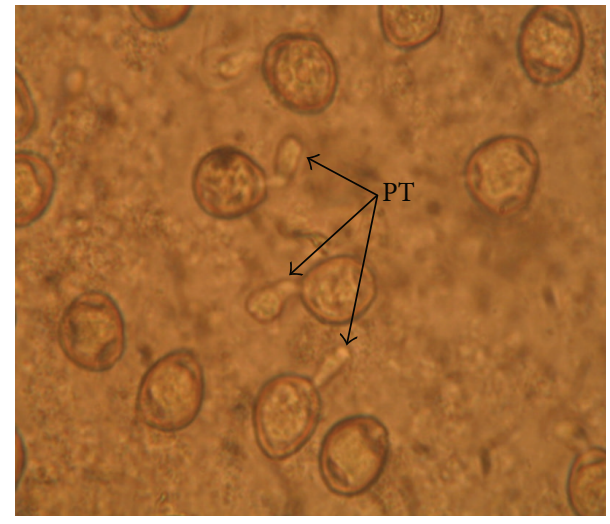

(a)

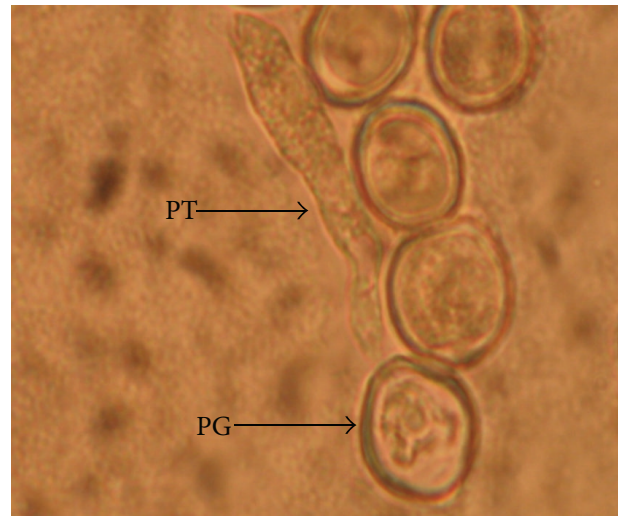

(b)

FIGURE 1: Germination of pollen grains for caprifig Jrani at $24 \mathrm{H}((\mathrm{a}), \times 40)$ and $48 \mathrm{H}((\mathrm{b}), \times 100)$ of incubation in a medium containing $5 \%$ sucrose, $5 \mathrm{ppm}$ boric acid $\left(\mathrm{H}_{3} \mathrm{BO}_{3}\right)$, and $1 \%$ agar, $\mathrm{pH}=5$, and temperature $=25^{\circ} \mathrm{C}$. PT: pollen tube; PG: pollen grain.

for the different caprifig cultivars were not synchronous and heterogeneous. In fact, in the same medium, we observed different pollen tube lengths. Under germination conditions described and starting from $24 \mathrm{H}$, the grains of pollen start to emerge a pollen tube where its length varied according to the incubation period (Figure 1).

Results showed significant differences $(P<0.01)$ among caprifig cultivars for germination rate and pollen tube length (Table 3 ). In all caprifig types, germination rate and pollen tube growth varied according to the incubation periods (Table 3 ). Germination rate after $24 \mathrm{H}$ ranged from 2.5 to $38.6 \%$. The lowest value was found in Djebba 4, while the highest one was obtained in Jrani. Germination rate after $48 \mathrm{H}$ varied between 10.7 (Djebba 4) and 70.9\% (Djebba 2). However, the caprifigs (Assafri, Djebba 1, and Djebba 2) constituted a separate group with relatively high germination levels. After $72 \mathrm{H}$, the highest germination percentage (72\%) was recorded in Assafri, whereas the lowest one (25\%) was found in Djebba 4 (Table 3). Pollen tube length after $24 \mathrm{H}$ ranged from $176.9 \mu \mathrm{m}$ (Djebba 4) to $518.8 \mu \mathrm{m}$ (Assafri). After $48 \mathrm{H}$, it varied from $300 \mu \mathrm{m}$ (Djebba 4 ) to $871.5 \mu \mathrm{m}$ (Jrani). The type Djebba 3 presented the shortest pollen tube length, whereas the caprifigs (Jrani and Djebba 1) have the longest ones. For pollen tube length after $72 \mathrm{H}$, the highest value $(960 \mu \mathrm{m})$ was always registered in Jrani, while the lowest one $(366 \mu \mathrm{m})$ was found in Djebba 4 (Table 3).

The germination percentage found in this study was in accordance with the results of Awamura et al. [22] in which caprifig pollen germination increased to above $70 \%$ by adding stigmatic exudates from long styled pistillate flowers to the culture medium. Similarly, it was showed that a low concentration of sucrose $(5 \%)$ and temperature of $30^{\circ} \mathrm{C}$ during 24-48 hours of incubation were effective for better pollen germination $[18,19]$. Contradictory to the germination studies mentioned above, it was reported that better pollen germination in caprifigs was obtained with $20 \%$ sucrose concentration [17].

\section{Conclusion}

In determining the pollen quality of caprifigs, viability tests are often considered to be faster and easier methods than the germination tests, since the effects of external factors such as temperature, humidity, and germinating media are minimized. Results of the present study strongly supported this approach. Either TTC or acetocarmine could be used in 
determining the pollen viability and to indicate germination status in caprifigs. The four caprifigs (Assafri, Jrani, Djebba 1, and Djebba 2) appear to have sufficient pollen viability and/or germination. All of them could be used on fig female pollination and breeding programs; however, this needs to be tested by in vivo pollinations for yield.

\section{Acknowledgments}

This study is part of research program of the Research Unit on Agrobiodiversity (UR03AGR04) financed by the Ministry of Higher Education and Scientific Research (Tunisia). Authors would like to thank Mrs. Asma Laarif and all farmers for their efficient collaboration.

\section{References}

[1] M. A. Flaishman, Z. Yablovich, S. Golobovich et al., "Molecular breeding in fig (Ficus carica) by the use of genetic transformation," Acta Horticulturae, vol. 798, pp. 151-158, 2008.

[2] X.-M. Yang, W. Yu, Z.-P. Ou, H.-L. Ma, W.-M. Liu, and X.L. Ji, "Antioxidant and immunity activity of water extract and crude polysaccharide from Ficus carica L. fruit," Plant Foods for Human Nutrition, vol. 64, no. 2, pp. 167-173, 2009.

[3] H. Lazreg Aref, B. Gaaliche, A. Fekih et al., "In vitro cytotoxic and antiviral activities of Ficus carica latex extracts," Natural Product Research, vol. 25, no. 3, pp. 310-319, 2011.

[4] M. Trad, C. Ginies, B. Gaaliche, C. M. G. C. Renard, and M. Mars, "Does pollination affect aroma development in ripened fig [Ficus carica L.] fruit?” Scientia Horticulturae, vol. 134, pp. 93-99, 2012.

[5] E. Stover, M. Aradhya, L. Ferguson, and C. H. Crisosto, "The fig: overview of an ancient fruit," HortScience, vol. 42, no. 5, pp. 1083-1087, 2007.

[6] F. Kjellberg, P.-H. Gouyon, M. Ibrahim, M. Raymond, and G. Valdeyron, "The stability of the symbiosis between dioecious figs and their pollinators: a study of Ficus carica L. and Blastophaga psenes L," Evolution, vol. 41, no. 4, pp. 693-704, 1987.

[7] M. Mars, B. Gaaliche, I. Ouerfelli, and S. Chouat, "Systèmes de production et ressources génétiques du figuier (Ficus carica L.) à Djebba et Kesra, deux villages de montagne au nord ouest de la Tunisie," Revue des Régions Arides, vol. 22, pp. 33-45, 2009.

[8] B. Gaaliche, M. Trad, and M. Mars, "Effect of pollination intensity, frequency and pollen source on fig (Ficus carica L.) productivity and fruit quality," Scientia Horticulturae, vol. 130, no. 4, pp. 737-742, 2011.

[9] T. Lahbib, Etude pomologique des variétés de figuier (Ficus carica L.) répertoriées au Sahel tunisien, Mémoire de Fin d'Etudes du Cycle de Spécialisation, INAT, Tunis, Tunisie, 1984.

[10] B. Gaaliche, O. Saddoud, and M. Mars, "Morphological and pomological diversity of fig (Ficus carica L.) cultivars in Northwest of Tunisia," ISRN Agronomy, vol. 2012, Article ID 326461, 9 pages, 2012.

[11] A. Oukabli, A. Mamouni M Laghezali, M. Ater, J. P. Roger, and B. Khadari, "Local caprifig tree characterization and analysis of interest for pollination," Acta Horticulturae, vol. 605, pp. 61-64, 2003.

[12] M. Mars, K. Chatti, O. Saddoud, A. Salhi-Hannachi, M. Trifi, and M. Marrakchi, "Fig cultivation and genetic resources in
Tunisia, an overview," Acta Horticulturae, vol. 798, pp. 27-32, 2008.

[13] A. B. Küden, S. Bayazit, and S. Çömlekcioglu, "Morphological and pomological characteristics of fig genotypes selected from Mediterranean and south east Anatolia regions," Acta Horticulturae, vol. 798, pp. 95-102, 2008.

[14] R. G. Stanley and H. F. Linskens, Pollen: Biology, Biochemistry, Management, Springer, New York, NY, USA, 1974.

[15] S. A. Khan and A. Perveen, "Germination capacity of stored pollen of Ficus carica (Moraceae) and their maintenance," Pakistan Journal of Botany, vol. 40, no. 6, pp. 2251-2254, 2008.

[16] W. B. Storey, "Figs," in Advances in Fruit Breeding, J. Janick and J. Moore, Eds., pp. 568-589, Purdue University Press, West Lafayette, Ind, USA, 1975.

[17] M. Ilgin, F. Ergenoglu, and S. Caglar, "Viability, germination and amount of pollen in selected caprifig types," Pakistan Journal of Botany, vol. 39, no. 1, pp. 9-14, 2007.

[18] N. Zeybekoğlu, A. Misirli, and R. Gulcan, "Researches on pollen germination ability of some caprifig varieties," Acta Horticulturae, vol. 480, pp. 125-128, 1998.

[19] U. Aksoy, B. Balci, H. Z. Can, and S. Hepaksoy, "Some significant results of the research-work in Turkey on fig," Acta Horticulturae, vol. 605, pp. 173-180, 2003.

[20] D. E. Parfitt and S. Ganeshan, "Comparison of procedures for estimating viability of prunus pollen," HortScience, vol. 24, pp. 354-356, 1989.

[21] I. Bolat and L. Pirlak, "An investigation on pollen viability, germination and tube growth in some stone fruits," Turkish Journal of Agriculture \& Forestry, vol. 23, pp. 383-388, 1999.

[22] M. Awamura, K. Shoda, and M. Hiramatsu, "In vitro germination of caprifig pollen grains using stigmatic exudate of a common fig as a promoter," Journal of the Japanese Society for Horticultural Science, vol. 63, no. 4, pp. 739-743, 1995. 


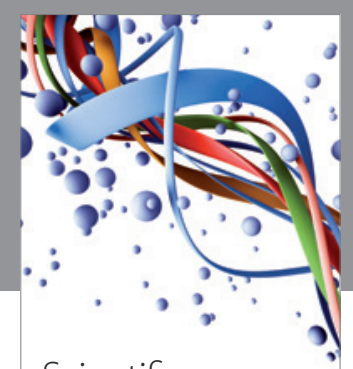

Scientifica
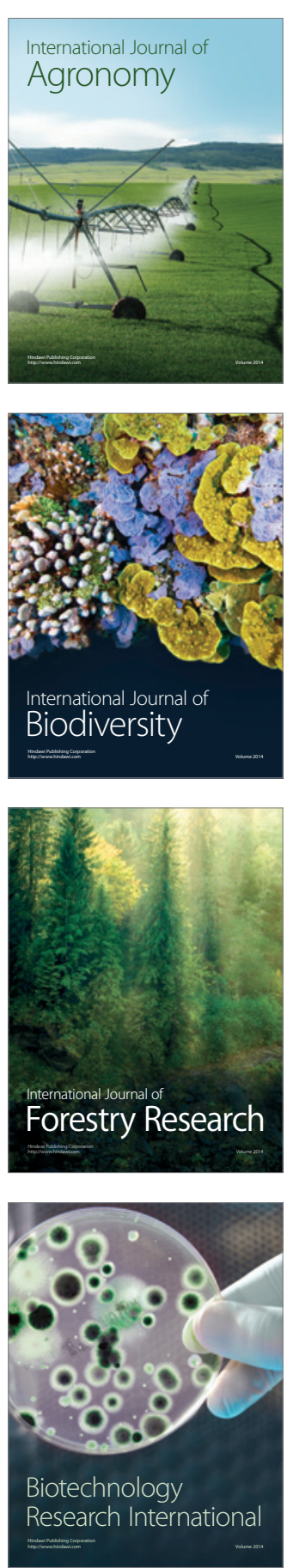
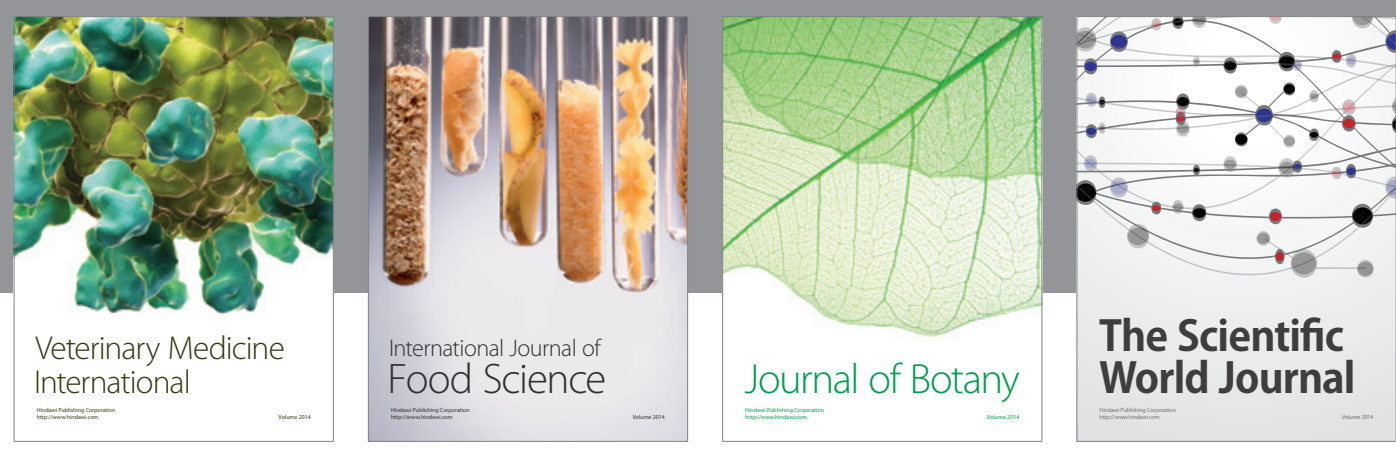

The Scientific World Journal
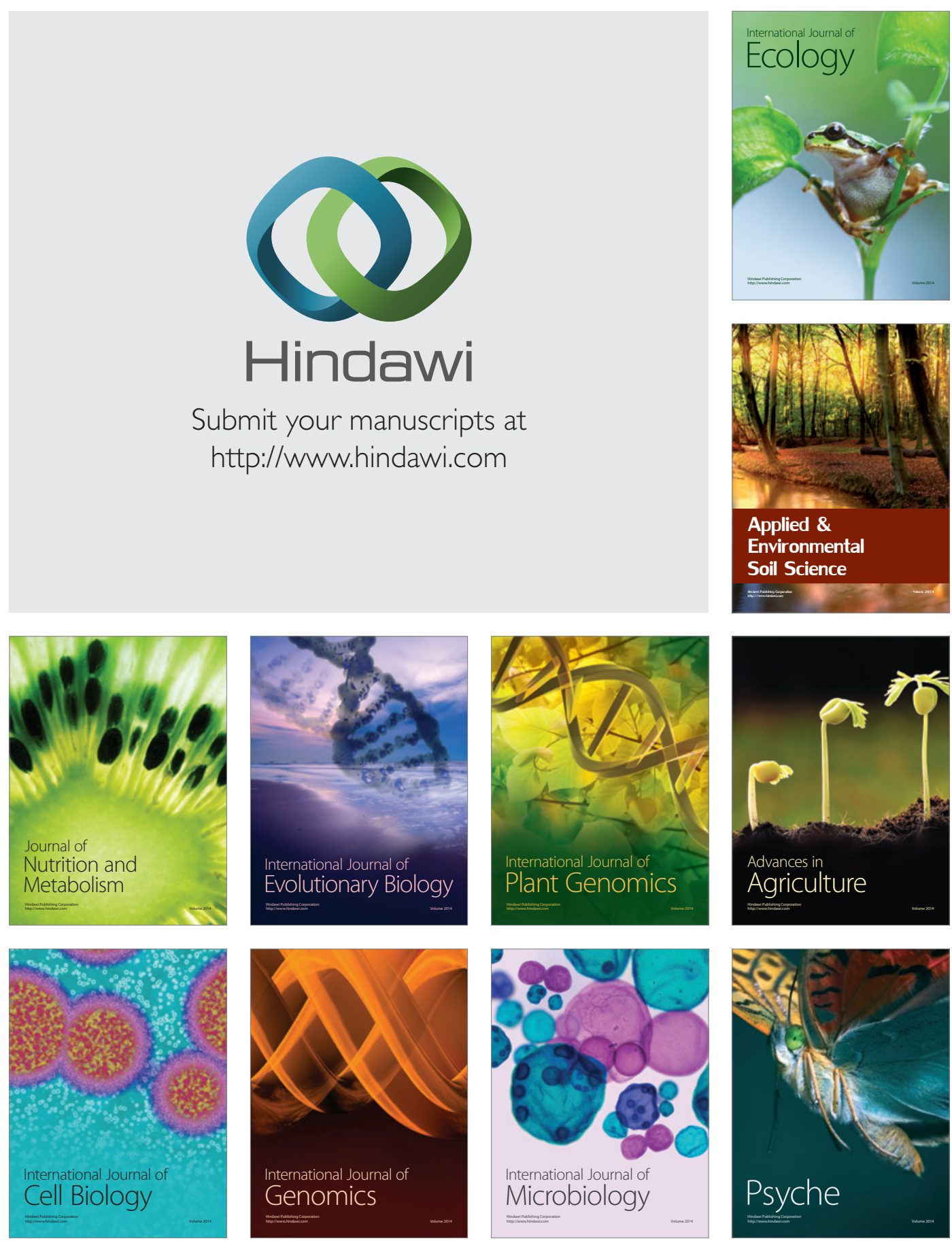